\title{
PENYULUHAN ASUPAN NUTRISI KACANG KEDELAI TERHADAP LEMAK PERUT MASYARAKAT DESA RIDAN PERMAI
}

\author{
Ramdhan Witarsa ${ }^{1}$, Fadhilaturrahmi ${ }^{2}$, Muhammad Syahrul Rizal $^{3}$ \\ ${ }^{1,2,3)}$ Program Studi PGSD, Fakultas Ilmu Pendidikan, Universitas Pahlawan Tuanku Tambusai \\ e-mail: drdadan19@gmail.com
}

\begin{abstract}
Abstrak
Penyuluhan asupan nutrisi kacang kedelai terhadap lemak perut masyarakat Desa Ridan Permai ini penting dilakukan dikarenakan banyaknya masyarakat yang memiliki skala lemak perut tinggi dan berbahaya. Skala lemak perut yang tinggi tersebut ditandai dengan buncitnya perut seseorang. Perut buncit inilah yang merupakan salah satu faktor penyebab penyakit-penyakit degenerative seperti diabetes, jantung, dan darah tinggi dimiliki oleh masyarakat di Desa Ridan Permai. Metode pengabdian masyarakat yang dilakukan adalah dengan pemberian penyuluhan akan pentingnya asupan nutrisi kacang kedelai terhadap skala lemak perut seseorang. Penyuluhan ini berisi bagaimana cara membuat olahan kacang kedelai menjadi susu dan shake yang kaya akan nutrisi dan dapat mengecilkan perut yang buncit. Hasil yang didapatkan dari kegiatan penyuluhan ini adalah bertambahnya pengetahuan masyarakat akan olahan kacang kedelai lainnya. Selama ini masyarakat hanya mengolah kacang kedelai menjadi tempe dan tahu saja. Dari hasil penelitian ini juga didapatkan semakin banyaknya masyarakat Desa Ridan Permai yang semakin peduli akan kesehatan diri dan keluarganya.
\end{abstract}

Kata kunci: Asupan, Nutrisi, Penyuluhan.

\begin{abstract}
It is important to do this counseling on the nutritional intake of soybeans on the stomach fat of the people of Ridan Permai Village because many people have a high and dangerous scale of abdominal fat. The high scale of belly fat is indicated by a person's belly. This distended stomach is one of the factors causing degenerative diseases such as diabetes, heart disease and high blood pressure in Ridan Permai Village. The method of community service that is carried out is by providing counseling on the importance of soybean nutrition on a person's stomach fat scale. This counseling contains how to make processed soybeans into milk and shakes that are rich in nutrients and can reduce a distended stomach. The results obtained from this outreach activity were increased public knowledge of other soy bean preparations. So far, people only process soybeans into tempe and tofu. From the results of this study, it was also found that the increasing number of Ridan Permai villagers who are increasingly concerned about their health and their families.
\end{abstract}

Keywords: Intake, Nutrition, Counseling.

\section{PENDAHULUAN}

Lemak perut merupakan lemak yang ada di sekitar perut seseorang. Lemak perut inilah yang menyebabkan buncitnya perut seseorang. Lemak perut merupakan sumber dari munculnya segala penyakit, terutama penyakit-penyakit degeneratif seperti: diabetes, jantung, dan darah tinggi. Tema pengabdian yang dilakukan dalam artikel ini adalah penyuluhan asupan nutrisi kacang kedelai terhadap lemak perut masyarakat Desa Ridan Permai. Hal ini dilakukan dikarenakan banyaknya masyarakat Desa Ridan Permai yang memiliki perut buncit dan banyak mengalami gangguangangguan kesehatan (Jati, 2014).

Gangguan-gangguan kesehatan yang dialami oleh kebanyakan masyarakat Desa Ridan Permai adalah gejala-gejala diabetes, jantung, darah tinggi, dan menurunnya daya tahan tubuh. Kondisi beberapa bulan terakhir yang masih dalam keadaan pandemi virus corona menambah resiko-resiko masyarakat terhadap kesehatan mereka. Upaya-upaya yang dilakukan salah satunya adalah dengan 
memasukan asupan nutrisi agar daya tahan tubuh dan kesehatannya lebih terjaga (P. N. Fatimah, Dieny, Murbawani, Fahmy, \& Tsani, 2018).

Salah satu materi yang diberikan dalam penyuluhan ini adalah pemberian informasi tentang skala lemak perut. Adapun skala lemak perut digambarkan sebagai berikut:

\begin{tabular}{|c|c|}
\multicolumn{2}{|c|}{ Tabel 1. Skala Lemak Perut } \\
\hline Skala & Kategori \\
\hline $1-5$ & Sehat Ideal \\
\hline $6-9$ & Tinggi \\
\hline $10-14$ & Bahaya \\
\hline $15-59$ & Sangat Bahaya \\
\hline
\end{tabular}

(Sumber: (Ratno \& Halimah, 2019))

Skala 1 - 5 dapat dikatakan lemak perut dalam batas sehat ideal, terus lakukan monitoring agar skala lemak perut sehat ideal ini tidak beranjak ke skala 6 keatas/kategori tinggi. Skala 6 - 9 dapat dikatakan lemak perut cukup tinggi, tetapi masih merasa sehat, perlu waspada dan harus dikurangi dengan menurunkan berat badan dan lemak perutnya. Apabila tidak dikontrol, penambahan skala lemak perut ini cepat bertambahnya dikarenakan pola makan yang semakin buruk. Skala 10 - 14 dapat dikatakan skala lemak perut tinggi dan bahaya. Skala ini diluar kisaran batasan sehat. Jika dibiarkan akan beresiko terhadap penyakit-penyakit degeneratif seperti diabetes, kanker, tekanan darah tinggi, jantung, dan penyakit-penyakit lainnya. Skala 15 - 59 dapat dikatakan skala lemak perut sangat bahaya. Pada skala ini tidak ada alasan untuk menunda apabila ingin menghabiskan sisa usia dengan sehat dan bugar. Ingat, penyakit degeneratif merupakan penyakit akibat kemunduran fungsi organ tubuh, pemulihannya memerlukan waktu, biaya pengobatannya mahal, dan perbaikan gaya hidup sehat sebelumnya sulit, serta kabar buruknya adalah sebagian besar tidak dapat pulih ke kondisi kesehatan seperti sedia kala (R. N. Fatimah, 2015)

Kegiatan pengabdian pada masyarakat yang pernah dilakukan sebelumnya adalah Penyuluhan Palawija Desa Ridan Permai untuk Ketahanan Pangan saat Pandemi Covid 19 (Witarsa, Fadhilaturrahmi, \& Rizal, 2020). Selama ini, palawija kacang kedelai hanya diolah menjadi tahu dan tempe. Kacang kedelai tidak pernah diolah menjadi susu dan shake, padahal kacang kedelai yang diolah menjadi susu dan shake sangat kaya akan nutrisi dan dapat meningkatkan daya tahan tubuh.

Pengabdian masyarakat melalui penyuluhan-penyuluhan ini sangat penting dilakukan agar kita mengetahui situasi dan kondisi yang terjadi di masyarakat. Dengan kita turun lapangan ke masyarakat, maka kita sebagai penyuluh akan mengetahui situasi dan kondisi yang sedang dialami masyarakat sehingga kita bisa berkontribusi didalamnya.

Tujuan pengabdian masyarakat ini diungkapkan sebagai berikut:

1. Adanya perubahan sikap dan mindset kelompok masyarakat sasaran sesudah dilakukannya Penyuluhan Asupan Nutrisi Kacang Kedelai di Desa Ridan Permai melalui Sistem Padat Karya dan Pendampingan Berkelanjutan juga semakin bertambahnya petani-petani muda di wilayah sekitar untuk mengolah lahan dan lingkungan menjadi lebih produktif.

2. Tersedianya bahan produksi palawija kacang kedelai yang lebih banyak guna memenuhi permintaan masyarakat (Witarsa \& Mufarizuddin, 2020).

3. Semakin bertambahnya pengetahuan masyarakat akan pentingnya asupan nutrisi dan pentingnya akan kesehatan tubuh pribadi dan keluarga.

\section{METODE}

Metode pengabdian masyarakat yang dilakukan adalah melalui pendidikan masyarakat berupa penyuluhan yang bertujuan untuk meningkatkan pemahaman serta kesadaran masyarakat akan materi-materi yang diberikan oleh tim penyuluh (Chrisanto, Sari, Hermawan, \& Andoko, 2020). 


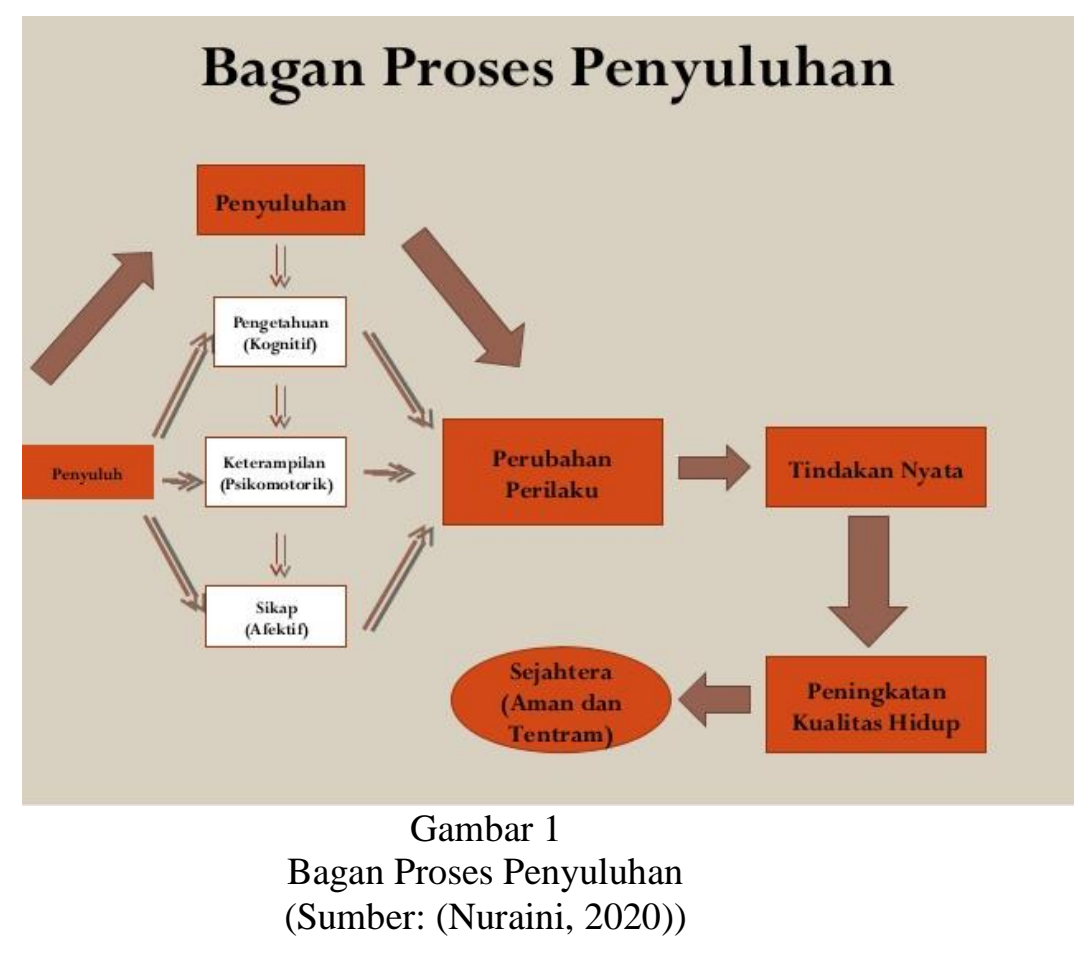

Berdasarkan bagan proses penyuluhan di atas, dapat dijelaskan bahwa Penyuluhan Asupan Nutrisi Kacang Kedelai terhadap Lemak Perut Masyarakat Desa Ridan Permai ini dilakukan dengan tahapan sebagai berikut:

1. Tim penyuluh melakukan penyuluhan yang berdiri dari tiga aspek sebagai berikut:

a. Tim penyuluh memberikan pengetahuan akan pentingnya asupan nutrisi kacang kedelai terhadap lemak perut dan dampaknya bagi kesehatan tubuh.

b. Tim penyuluh kemudian memberikan keterampilan bagaimana cara mengolah kacang kedelai menjadi susu dan shake yang kaya akan nutrisi serta bisa dikonsumsi dengan baik untuk kesehatan tubuh.

c. Tim penyuluh memberikan contoh hasil sikap masyarakat yang sudah mengkonsumsi shake kacang kedelai secara disiplin dan konsisten.

2. Dari penyuluhan yang telah dilakukan, tim penyuluh mengamati perubahan perilaku yang diharapkan, yaitu memberikan asupan nutrisi yang bermanfaat bagi tubuh.

3. Tim penyuluh mengamati perubahan-perubahan perilaku tersebut dan diharapkan dapat diterapkan pada tindakan nyata keseharian.

4. Tim penyuluh mengamati secara periodik peningkatan kualitas hidup masyarakat melalui pengukuran skala lemak perut secara bertahap dan pengecekan kesehatan secara umum.

5. Tim penyuluh mengamati hasil dari penyuluhan yang sudah dilakukan, dengan harapan kesehatan masyarakat semakin meningkat.

\section{HASIL DAN PEMBAHASAN}

Pelaksanaan pengabdian masyarakat ini dilakukan di Aula Kantor Desa Ridan Permai Kecamatan Bangkinang Kota, Kabupaten Kampar, Provinsi Riau. Berikut lokasi sasaran tempat pengabdian dilaksanakan: 


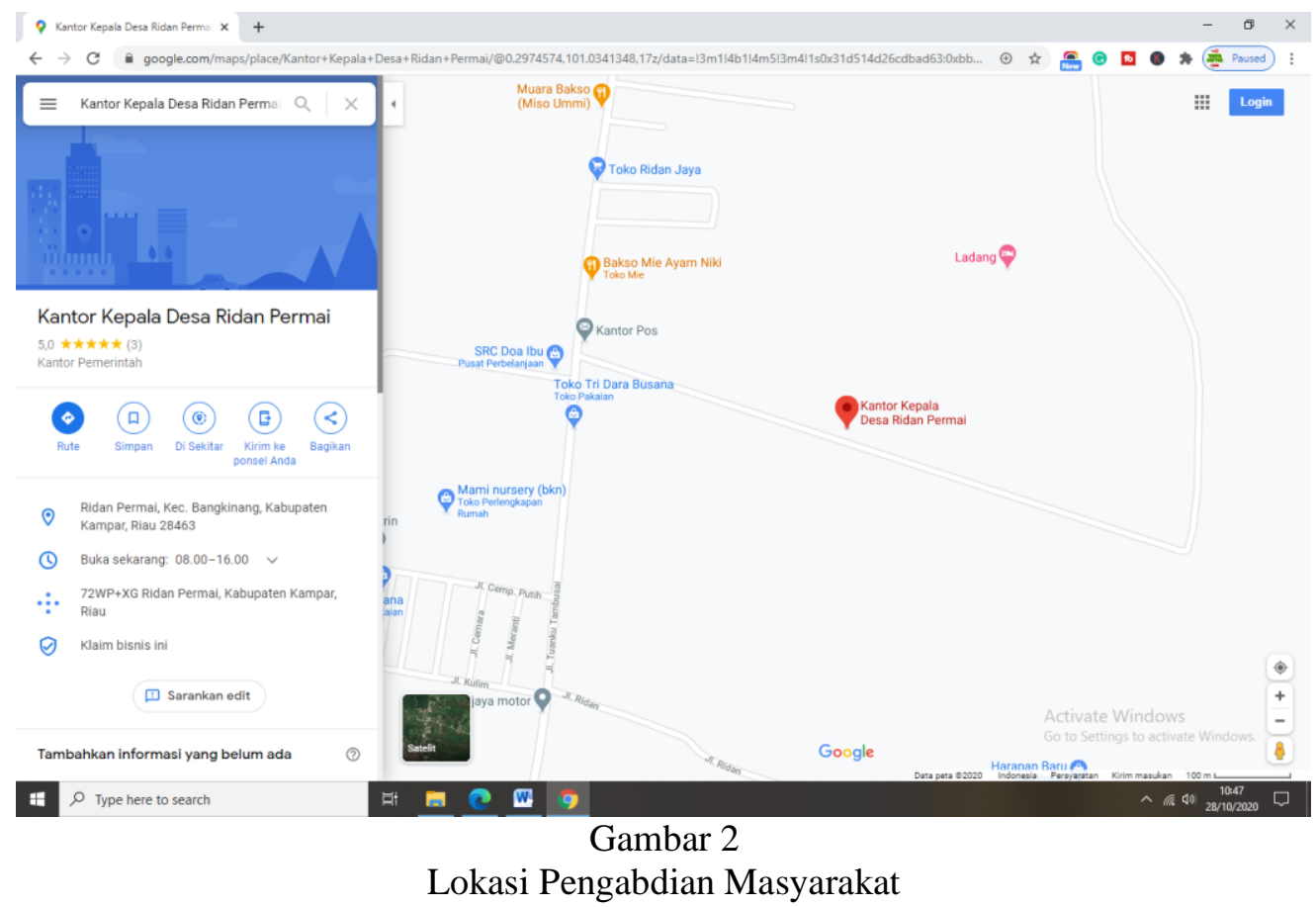

Pelaksanaan hasil penyuluhan secara umum dapat dikatakan lancar dan sesuai dengan tahapan yang dijelaskan pada langkah-langkah pengabdian yang direncanakan sebelumnya. Prosedur pertama yang dilakukan oleh tim penyuluh adalah memberikan penyuluhan berupa pengetahuan akan pentingnya asupan nutrisi kacang kedelai terhadap lemak perut dan dampaknya bagi kesehatan tubuh. Kegiatan tersebut didokumentasikan pada Gambar 3 dibawah ini:

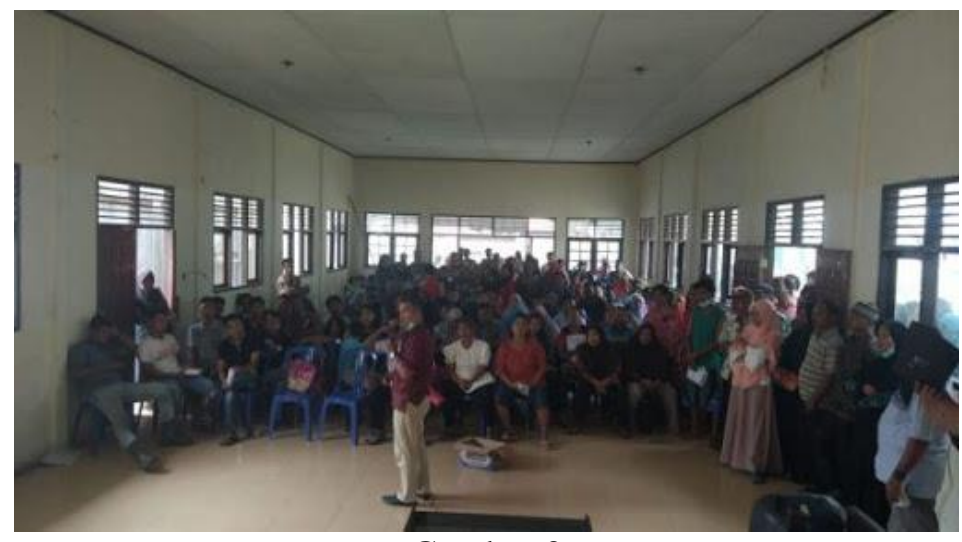

Gambar 3

Pelaksanaan Kegiatan Penyuluhan Pentingnya Asupan Nutrisi Kacang Kedelai

Pada Gambar di atas nampak bahwa masyarakat Desa Ridan Permai sangat antusias mengikuti penyuluhan ini. Penyuluhan ini dihadiri juga Kepala Desa Ridan Permai dan jajarannya. Aula desa yang ada tidak cukup repserentatif untuk kegiatan ini dilakukan. Perlu adanya jadwal dan tahapan agar pelaksanaan penyuluhan bisa berlangsung secara efektif. Antusiasme ini ditunjukkan warga dikarenakan selama ini minim akan penyuluhan kesehatan yang sifatnya praktis dan berhubungan dengan kegiatan harian mereka yang rata-rata berprofesi sebagai petani palawija.

Tahap kedua yang dilakukan oleh tim penyuluh adalah tim penyuluh memberikan keterampilan bagaimana cara mengolah kacang kedelai menjadi susu dan shake yang kaya akan nutrisi serta bisa dikonsumsi dengan baik untuk kesehatan tubuh. Kegiatan tersebut didokumentasikan pada Gambar 4 dibawah ini: 


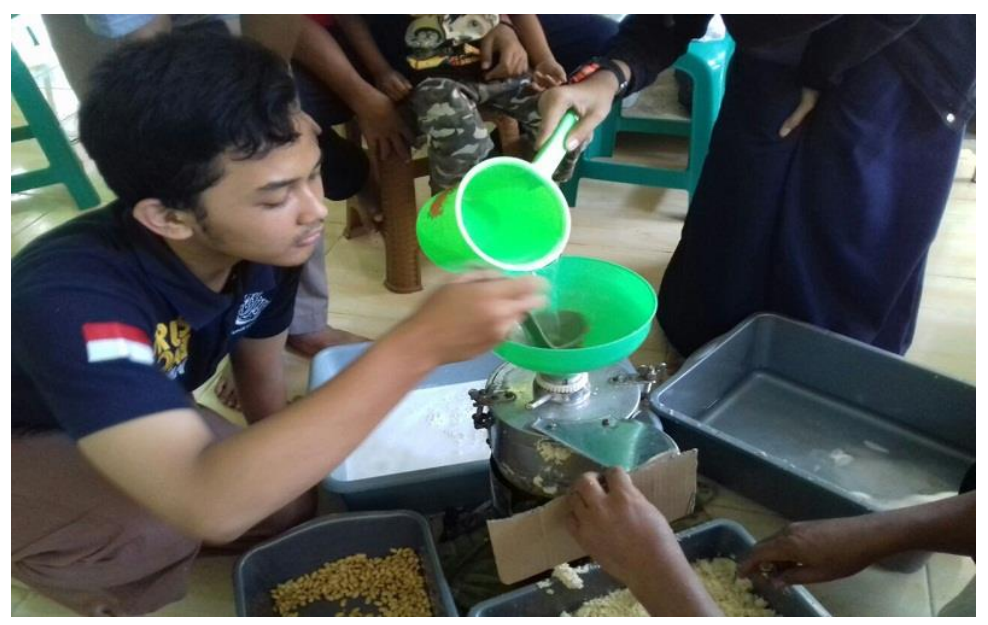

Gambar 4

Workshop Pembuatan Susu dan Shake Kacang Kedelai

Pada Gambar di atas nampak bahwa masyarakat Desa Ridan Permai sangat antusias mengikuti penyuluhan ini. Penyuluhan ini dihadiri juga Kepala Desa Ridan Permai dan jajarannya. Pada pelaksanaan workshop ini sudah dilakukan secara bertahap. Hal ini dilakukan agar tidak terjadi penumpukan warga dan agar workshop bisa berlangsung secara efektif. Workshop ini dilakukan maksimal diikuti oleh 20 orang warga.

Tahap ketiga adalah tim penyuluh memberikan contoh hasil sikap masyarakat yang sudah mengkonsumsi shake kacang kedelai secara disiplin dan konsisten. Contoh hasil salah satu warga masyarakat yang sudah mengkonsumsi shake kacang kedelai dapat dilihat pada Gambar 5 berikut:

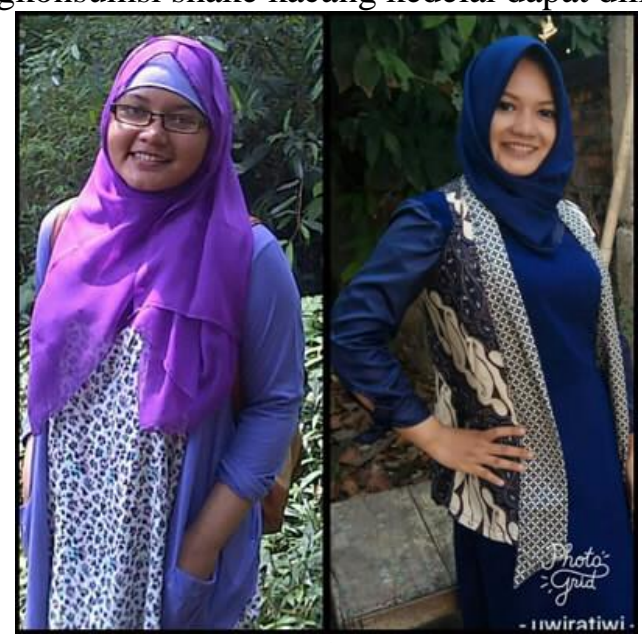

Gambar 5

Hasil dari Mengkonsumsi Susu dan Shake Kacang Kedelai secara Disiplin dan Konsisten

Dari Gambar 5 di atas nampak salah satu hasil dari mengkonsumsi susu dan shake kacang kedelai secara disiplin dan konsisten. Terjadi penurunan berat badan yang cukup siginifikan. Selama satu bulan program sehat tersebut, bisa turun berat badan hingga $10 \mathrm{~kg}$. Tentu saja hasil yang didapatkan setiap warga berbeda-beda. Hasil lainnya bisa dilihat pada Tabel 2 dibawah.

Dari penyuluhan yang telah dilakukan, tim penyuluh mengamati perubahan perilaku yang diharapkan, yaitu memberikan asupan nutrisi yang bermanfaat bagi tubuh.Tim penyuluh juga mengamati perubahan-perubahan perilaku tersebut dan diharapkan dapat diterapkan pada tindakan nyata keseharian. Kebiasaan yang lama dan digantikan dengan kebiasaan yang baru memanglah tidak mudah dan memerlukan usaha yang maksimal. Berikut hasil dari mengkonsumsi susu dan shake kacang kedelai secara rutin dan konsisten: 
Tabel 2

Skala Lemak Perut Warga Desa Ridan Permai

\begin{tabular}{|c|c|c|c|c|}
\hline \multirow{2}{*}{ No. } & \multirow{2}{*}{ Kode Warga } & \multicolumn{2}{|c|}{ Skala Lemak Perut } & \multirow{2}{*}{ Keterangan } \\
\cline { 2 - 4 } & & Sebelum & Sesudah & \\
\hline 1 & KKF & 13 & 9 & Tinggi \\
\hline 2 & NMS & 14 & 9 & Tinggi \\
\hline 3 & JDG & 15 & 9 & Tinggi \\
\hline 4 & GET & 15 & 9 & Tinggi \\
\hline 5 & NDH & 6 & 9 & Tinggi \\
\hline 6 & CDG & 7 & 4 & Sehat Ideal \\
\hline 7 & DGH & 9 & 5 & Sehat Ideal \\
\hline 8 & OHG & 10 & 5 & Sehat Ideal \\
\hline 9 & LDK & 8 & 8 & Tinggi \\
\hline 10 & HSR & 6 & 5 & Sehat Ideal \\
\hline 11 & BER & 7 & 5 & Sehat Ideal \\
\hline 12 & SBD & 9 & 5 & Sehat Ideal \\
\hline 13 & WER & 6 & 7 & Tinggi \\
\hline 14 & LTK & 7 & 5 & Sehat Ideal \\
\hline 15 & ASQ & 6 & 4 & Sehat Ideal \\
\hline 16 & MKS & 7 & 5 & Sehat Ideal \\
\hline 17 & NDF & 6 & 5 & Sehat Ideal \\
\hline 18 & NSG & 7 & 5 & Sehat Ideal \\
\hline 19 & JRG & 8 & 5 & Sehat Ideal \\
\hline 20 & TRR & & 5 & Sehat Ideal \\
\hline
\end{tabular}

Berdasarkan Tabel 2 di atas dapat kita ketahui bahwa dari 20 orang warga masyarakat yang ikut dalam program sehat perut ini didapatkan 13 orang yang memiliki skala lemak perut sehat ideal, padahal sebelumnya ke13 orang ini memiliki skala lemak perut pada kategori tinggi. Apabila dihitung dengan skala persentase, asupan nutrisi shake kacang kedelai ini memberikan tingkat keberhasilan $65 \%$. Tujuh orang lainnya juga mengalami penurunan skala lemak perut yang cukup baik, meskipun belum mencapai kategori sehat ideal. Apabila kebiasaan yang baru tersebut terus dijalankan, buka tidak mungkin keadaan kesehatan ketujuh orang tersebut juga akan mencapai kategori sehat ideal.

Tim penyuluh mengamati secara periodik peningkatan kualitas hidup masyarakat melalui pengukuran skala lemak perut secara bertahap dan pengecekan kesehatan secara umum. Tim penyuluh mengamati hasil dari penyuluhan yang sudah dilakukan, dengan harapan kesehatan masyarakat semakin meningkat. Sampai dengan artikel ini diterbitkan, kebiasaan-kebiasaan baru yang warga lakukan semakin membaik dan bisa menunjukkan arah yang jauh luas lagi.

\section{SIMPULAN}

Berdasarkan hasil pengabdian yang sudah dilakukan, penyuluhan asupan nutrisi kacang kedelai terhadap lemak perut masyarakat Desa Ridan Permai didapatkan bahwa semakin bertambahnya pengetahuan masyarakat akan olahan kacang kedelai lainnya. Selama ini masyarakat hanya mengolah kacang kedelai menjadi tempe dan tahu saja. Dari hasil pengabdian ini juga didapatkan kesimpulan semakin banyaknya masyarakat Desa Ridan Permai yang semakin peduli akan kesehatan diri dan keluarganya. Ini dibuktikan dengan semakin banyaknya warga Desa Ridan Permai yang memiliki skala lemak perut dalam skala 1-5 (sehat ideal).

\section{SARAN}

Saran-saran yang bisa diberikan diungkapkan sebagai berikut: pelaksanaan penyuluhan sebaiknya dilakukan bertahap dengan memperhatikan jumlah peserta yang hadir. Perlu pembatasan jumlah masyarakat yang hadir maksimal 20 orang agar penyuluhan bisa diselenggarakan lebih kondusif dan masyarakat bisa fokus terhadap apa yang disampaikan. 


\section{UCAPAN TERIMA KASIH}

Tim penulis mengucapkan terima kasih kepada Universitas Pahlawan Tuanku Tambusai dan Desa Ridan Permai yang telah memberi dukungan dana dan moril terhadap terlaksananya pengabdian masyarakat ini. Tim penulis juga mengucapkan terima kasih kepada Pengelola Community Development Journal yang telah memberi review dan masukan atas terbitnya artikel ini.

\section{DAFTAR PUSTAKA}

Chrisanto, E. Y., Sari, R. Y., Hermawan, D., \& Andoko. (2020). PENYULUHAN PENTINGNYA PENCEGAHAN DAN PENGOBATAN PENYAKIT DIABETES MELLITUS GANG MAWAR KEMILING BANDAR LAMPUNG WILAYAH KERJA PUSKESMAS KEMILING BANDAR LAMPUNG. Jurnal Kreativitas Pengabdian Kepada Masyarakat (PKM), 3(1), 62-66.

Fatimah, P. N., Dieny, F. F., Murbawani, E. A., Fahmy, A., \& Tsani, A. (2018). Latihan Yoga terhadap Berat Badan, Persen Lemak Tubuh, dan Lingkar Perut pada Wanita Dewasa. 14(4), 131-139.

Fatimah, R. N. (2015). DIABETES MELITUS TIPE 2. Jurnal J Majority, 4(5), 93-101.

Jati, L. U. (2014). Perbedaan Asupan Lemak, Lingkar Pinggang dan Persentase Lemak Tubuh pada Wanita Dislipidemia dan Non Dislipidemia. Jurnal Kesehatan Masyarakat (e-Journal), 2(5), 292-299.

Nuraini. (2020). SOSIALISAI KESEHATAN TENTANG ISPA DAN PEMERIKSAAN FISIK DADA DAN THORAKS DI WILAYAH RW.02, KELURAHAN KEBON BESAR KECAMATAN BATUCEPER. Jurnal Kreativitas Pengabdian Kepada Masyarakat (PKM), 3(1), 80-86.

Ratno, P., \& Halimah, N. (2019). PERBEDAAN PENGARUH LATIHAN PLANK KNEE TO ELBOW, MOUNTAIN CLIMBER, DAN BICYCLE CRUNCH TERHADAP PERUBAHAN LINGKAR PERUT PADA REMAJA PUTRI SMA HANG TUAH BELAWAN. Jurnal Ilmu Keolahragaan, 18(1), 54-62.

Witarsa, R., Fadhilaturrahmi, \& Rizal, M. S. (2020). PENYULUHAN PALAWIJA DESA RIDAN PERMAI UNTUK KETAHANAN PANGAN SAAT PANDEMI COVID 19. Communnity Development Journal, 1(2), 151-156. Retrieved from https://journal.universitaspahlawan.ac.id/index.php/cdj/article/view/842/699

Witarsa, R., \& Mufarizuddin. (2020). PENYULUHAN PALAWIJA DESA RIDAN PERMAI UNTUK EKSISTENSI KEANEKARAGAMAN HAYATI SUMBER PANGAN. Communnity Development Journal, 1(1), 36-40. Retrieved from https://journal.universitaspahlawan.ac.id/index.php/cdj/article/view/524/452 